BROOYKHAVEM MATIONAI IABORATORY

Associated Universities, Inc.

Upton, Hew York 11973

Department of Applied science

Radiation Division

Informal Report

\title{
FRACTURE ENERGY AND STRENGTH OF POLYMER IMPREGHATED CEMENT
}

A. Auskern and $M$. Horn

NOTICE

This report was prepared if an eccount of work This report was prepared States Government. Nothes the United States nor the United Stutes Atomic Eneray the United States nor the their employees, nor any of Comintesion, nor any of their employees, not any of their contractors, subcontractors, of the em employces, makes any wartanty, express or implied, or assumes any legel linbility or tesponsibility for the accurecy, completeness of usefulneas of any information, appnintus, product or process disclowed, or represents that its use

February 1974

NOTICE

This report was prepared as an acsount of work sponsored by the United States Government. Neither the United states nor the United States Atomic Energy Commission, nor any of their employees, nor any of their contractors, subcontractors, or their employees, makes any warranty, express or implied, or assumes any legal liability or responaibility for the accuracy, completeness or usefulness of any information, apparatus, product or process disclosed, or representa that ita use wóuld not infringe privately owned rights. 
FRACTURE ENERGY AND STREAGTH OF POLYMER IMPREGAATED CEMEAT

\author{
A. Aunkern and $w$. Horn \\ Brookhaven Mational Laboratory \\ Upton, Law York 11973
}

\title{
ABSTRACT
}

The fracture energy, or effective surface energy of hardened cement paste and polymex-impregnated hardened cement paste, was measured by an analytical method. The fracture energy of polymer impregnated hardened cement paste is considerably higher than the unimpregnated paste $\left(7.5 \times 10^{4}\right.$ to $0.91 \times 10^{4}$ erga/ $\left./ \mathrm{cm}^{2}\right)$. The increase appears to be entirely due to the polymer contribution. The results predict a factor of 5 improvement in the fracture strength of hardened cement paste upon polymer impregnation. 


\section{Introduction}

It has been known for some time that the impregnation of concrete by a liquid monomer followed by in situ polymerization of the monomer results in a material with vastly improved mechanical, elantic, and durability properties $(1,2,3,4)$. For a typleal fog or water cured portland cement concrete of compressive strength $\sim 350 \mathrm{kgm} / \mathrm{cm}^{2}$ ( $\left.5000 \mathrm{psi}\right)$ the compressive and tensile strengths, upon polymer impregnation, increase by factors of 4-5 and Young's modulus increases by 2-3 times. A relatively anall volume of polymer is responsible for this increase; typically 10-15 volume \%. Since the cement phase of concrete is porous, it is in this phase that the polymer ie concentrated. The concentration of polymar in the cement phase can be between $\sim$ 30-40 volume $\%$, depending upon the cement con-. tent, water-cement ratio, and air content. Earlier work concludes that the effect of polymer impregnation is to increase the strength and modulus of the cement phase, and to improve the bonding between the cement and aggregate phased $(2,5)$. It was also demonstrated that roung's modulus of polymer impregnated cement and mortar could be predicted from composite theory (5). That work indicated an improvement in modulus by a factor of about 3 upon impregnation of hardened sement paste with methyl methacrylate polymer.

The fracture energy (or effective aurface energy) is 
generally defined as the work required to create a unit area of new fracture surface. It is the surface energy value used in the Griffith equation, and thus is of fundamental importance in elvcidating the mechanical properties of brittle materials (6). By comparing the fracture energy of polymor impregnated harduned cement paste with that of unimpregnated hardened cement paste, it should be possible, through the Griffith equation, to rationalize the observed atrength improvements of polymer impregnated hardened cement and polymer imprognated concrete.

Only a few measurements of the effective suxface energy of hardened cement paste have been reported $(7,8,9)$. Ho measurements of the effective surface energy of polymer impregnated cement have been found. In general the effective ourface onorgy of hardened cement paste is around that of glass, 5-10 $\times 10^{3}$ ergs $/ \mathrm{cm}^{2}(6)$. It appears to increase sightly with duration of cure, and is about the same for mortar. It is about $50 \%$ greater for concrete (7).

In the present work measurements are made of the fracture energy of a hardened cement paste and a polyner impregnated hardened cement paste. An attempt is then made to rationalize the improvement in strength upon polymer impregnation ueing the Griffith equation. This has been used by Tazawa and Kobayashi (10). Their observations will be discussed in the appropriate section. 


\section{Experizental}

Rectangular cament bars, $1.27 \mathrm{~cm} \times 1.27 \mathrm{~cm} \times 7.62 \mathrm{~cm}$, water to cement ratio of 0.5 , were cast from a type II A portland cement. The bars were demolded after one day, and were cured under water at room temperature for 13 additional days. The specimens wore allowed to dry at room temperature for a week, and then were slowly heated $\left(3\right.$ days) to $100^{\circ} \mathrm{C}$ for an additional week.

After drying, half the group was impregnated with methyl methacrylate monomer which was then polymerized. Impregnation was done by first evacuating the samples with a fore-pump, adding the monomer (which contained $0.5 \%$ AIBN" catalyst), and soaking for $0.5 \mathrm{hr}$. with an overpressure of $25 \mathrm{psi}$ argon. 2 the monomer filled bars were then individually wrapped in aluminum foil, sealed in a polyethylene bag, and immersed in a water bath at $80^{\circ} \mathrm{C}$ overnight. The impregnated samples had an average weight loading of $27.9 \pm 0.2 \%$ which is equivalent to a volume concentration of $35 \cdot 8 \pm 0.3 \%$.

Young's modulus was measured for all the specimens by loading the bars in 3 point bending to a load estimated to be $25 \%$ of the fracture load.

Effeetive surface energy measurements were made by the analytical method described by Davidge and Tappin (6) . Cracka * azobis isobutyronitrile

* Average deviation from the mean. 
were cut in the samples with $0.03 \mathrm{~cm}$ thick dianond wheel. The crack depth to sample depth was 0.3. The expresing uned in

$$
y=\frac{g\left(1-v^{2}\right) g^{2} I^{2} E(c / a)}{B E b^{2}(a-c)^{3}}
$$

where $Y$ is the effective surface energy; $v$ is Poisson's ratio; P Is the load at fracture; 1 is the opan; $f(c / d)$ is a dimensionles: parameter equal to 0.41 for $c / d=0.3 ; \mathrm{B}$ is Young': modulus, $b$ is the breadth; $d$ is the depth; and $c$ is the machined crack depth. Polsson' ratio for hardened cement paste was taken as 0.25 (12). For the polymer impregnated paste, Poisson'z ratio of 0.32 was used to reflect an approximate $25 \%$ increase in Podeson's ratio when concrete is polymer impregnated (12).

The specimen: were fractured in 3 point loading in an Instron testing machine at a crosuhead opeed of $0.0051 \mathrm{~cm}$ fer minute. Typical load-deflection curvas are shown in Fig. 1. Failure in the unimpregnated specimens was in a controlled manner.

\section{Results and Discuseion}

The fact that the specimens were dried regulted in the presence of some unavoidable cracks. The drying was done in order to permit full polymer impregnation and to simulate more closely the conditions under which polymer impregnated concrete and control concrete have been evaluated. The presence of these drying cracks did not appear to influence $P$, the failure load 
FIG. 1

Typical 1oad-deflection cuzver for fracture specimens.

or c, the machined arack depth in equation 1 . With two impregnated amples after most of the load had falien off, an arresting effoct was noted which might have been due to a crack perpendicular to the propagating crack. This can be seen in Fig. 1 .

The machined crack had a rather square bottom, and the failure crack always propagated from a corner of the machined crack.

The effective surface energies for the unimpregnated and impregnated samples were calculated using equation 1 with the measured Young's modulus for each sarple. These results are tabulated below. 


\section{TABLE I}

Motulus and Fracture Bnergy

Ioading $\frac{\text { Young's Modulus }}{\left(\mathrm{Kgm} / \mathrm{cm}^{2}\right)} \frac{\text { Fracture Energy }}{\left(\mathrm{exg} / \mathrm{cm}^{2}\right)}$

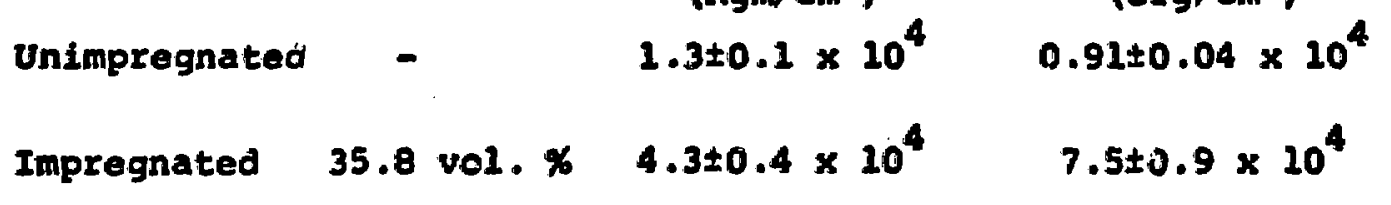

* Average of 5; \pm average deviation from the mean.

The work most directly comparable to that here is the work of Cooper and Figg and of Moavenzadeh and Kuguel. Cooper and Figg (8) measured, by the work of fracture method, the effective surface energy of wet and dried (at roon temperature) hardened cement pastes. They used a water/coment ratio of 0.5 , and their gamples were cured for 40 days. They measurea a buriace energy of $1.2 \times 10^{4} \mathrm{erg} / \mathrm{cm}^{2}$ for the wet samples and $1.5 \times 10^{4}$ erg/cm ${ }^{2}$ for dry samples. These values are similar to, but somewhat greater than, the results here for unimpregnated samples. Moavenzadeh and Kuguel (7) report effective Burface energies calculated from work of fraccure, cxitical strain energy release, and critical stress intensity factor experimenice. For a hardened cement paste of $w / c=0.5$ cured for 14 days the range of effective surface energies is from $0.23 \times 10^{4}$ to $.42 \times 10^{4}$ erg $/ \mathrm{cm}^{2}$, which is about a quarter to a half the values measured here.

Brown (9) measured the fracture toughness of wet hardened 
cement pastes $(w / c=.35,84$ days cure) in a masiner that accounted for slow crack growth prior to failure. His resulta can be compared with the critical otrase intensity factore of Moavenzadeh and Kuguel (7), but only indirectly to the fracture energy. He observed a critical otress intensity factor of 390 $1 \mathrm{~b} / \mathrm{in}^{3 / 2}$ compared to $150 \mathrm{lb} / \mathrm{in}^{3 / 2}$ by Moavenzadeh and Kuguel. This suggests that the offective surface energy of Brown's sample is $\sim 6$ times that of Moavenzadeh and Kuguel $(7)$, or in the range $1.5-2.8 \times 10^{4} \mathrm{org} / \mathrm{cm}^{2}$. This is somewhat higher than that of Cooper and Figg (9) and the present work.

The presence of polymer in the cement results in an eightfold increase in fracture energy. Since polymer fills the continuous pore structure of the hardened cement, during fracture that polymer along the duvancing crack path is fractured. The fracture energy of polymethyl methacrylate is $6 \times 10^{5}$ ery/cm (6), which is around 50 times that of unimpregnated cement. If it is assumed that one-third of the polymer is effectively perpendicular to the fracture surface, then the energy to fracture this much polymer is $1 / 3(0.358)\left(6 \times 20^{5}\right) \mathrm{erg} / \mathrm{cm}^{2}$ or $7.2 \times 10^{4} \mathrm{erg} / \mathrm{cm}^{2}$. This is essentially the fracture energy of polymer impregnated cement. So the fracture energy of polymer impregnated cement is due almost entirely to the fracture of the polymer; the fracture of hardened cement makes a negligible contribution.

Tazawa and Kobayshi (10) assumed for polymer inpregnated mortar and concrete that all the polyther is in the form of 
spheres, filling the aix yoids of the matrix. They then computed by an additive law the effective fracture energy of poiymer impregrated mortar and concrete, using the fracture energy values from refexence. (7). They reach similar conclusion, that the fracture energy of the impregnated materiale is domineted by the fracture energy of the polymer. Their model, however, appears to be over simplified. Firet, most of the polymer resides in sapillary pores, not air voids (5). Second, microscopic observation of fracture surfacfs of polymer impregnated cements and mortars shows that fracture surfaces rarely pass through polymer filled voids. They generally pase around theze voids. It has been observed that these voids are ueually lined with a thin layer of polymer (13). Figs, 2 and 3 are rcanning electron micrographs of fracture surfaces observed in this study. These areas were selected because they contain small spherical voids. Fig. 2 is of the unimpregnated sample, and the fracture surface passes right through the void. Fig. 3 is from the polymer filled sample. The impinging crack passes around the polymer filled (or partially filled) void. So the high concentration of polymer in this yoid did not contribute to the measured fracture energy. Note the background features in these figures. Fig. 3 appears to have a somewhat less rough texture, but it is difficult to positively identify the polymer phase.

with a knowledge of the effective surface energies, the strength improvement to be expected upon polymer filling may be 


\section{EIG. 2}

Fracture surface of unimpregnated sample showing an air void of about 25 microns diameter.

FIG. 3

Fracture surface of impregnated sample showing an air void containing polymer. 
predicted using Griffith's equation. This equation is

$$
0=\left(\frac{E_{Y}}{C}\right)^{1 / 2}
$$

where $\sigma$ is the fracture stress, $A$ is a constant depending on the sample geometry, and $C$ is the intrinsic crack or flaw length. Using the subscript 1 for impregnated and $u$ for unimpregnated,

$$
\frac{\sigma_{i}}{\sigma u}=\left(\frac{E_{i}}{E_{u}}\right)^{1 / 2}\left(\frac{y_{i}}{\gamma_{u}}\right)^{1 / 2}\left(\frac{\mathrm{cu}_{\mathrm{u}}}{\mathrm{C}_{1}}\right)^{1 / 2}
$$

The moduli and the surface energies are known. Tazawa and Kobayashi $(10)$ in their analysis assumed the intrinsic flaws are the spherical voids, and that they are reduced in size upon polymor filling by an amount equal to the polymerization and thermal ohrinkages - about 30\%. It is anumed here that the presence of polymer does not affect the flaw length. Equation 3 can then be evaluated:

$$
\sigma i / o u=(3.31)^{1 / 2}(8.24)^{1 / 2}(1)^{1 / 2}=5.2
$$

These results predict a factor of $\sim 5$ improvement in the strength of hardened cement parte upon polymer impregnation. This seems a not unreasonable prediction, in view of the widely published results for polymer impregnated mortars and concretes (1-4, 12) and some compressive strength results for cement pastes (2). The predicted strength improvement will probably 
be 1 ess for lower water/cement ratio pastes because $Y_{i}$ will be lower due to the lower polymer content. This would be consistent with the observation that weaker pastes, mortars, and concretes show a greater relative strength improvement than stronger ones upon polymer impregnation $(3,4,12,13)$.

\section{Conclusions}

The fracture energy, or effective aurface energy of polymer impregnated cement is conaiderably higher than the unimpregnated cement and appears to be essentially all contributed by the polymer phase.

The Friffith equation predicts a not unreasonable increase in fracture strength of about 5 times for the materials tested here. The increase would be less for less porous cement. pastes. The increase in fracture strength is due largely to the fracture energy increase, but there is also a significant contribution from the increase in Young's modulus.

\section{Acknowledgment}

The authors would like to acknowledge John J. Kelsch for taking the scanning electron micrographs.

\section{References}

1. M. Steinberg et al., Concrete-Polymer Materials, First Topical Report, BNL 50134 (T-509), Brookhaven National Iaboratory, Upton, N.Y., Dec. 1968.

2. A. Auskern and . Horn, J. Amer. Ceram. Soc., 54, 282, 1971.

3. D. G. Manning and B. B. Hope, Cement and Concrete Research, 1. 631, 1971. 
4. J. T. Dikeau et al, Concrete-Polymer Materiala, Third Topical Report, REC-ERC-71-6 and BNR 50275 (T-602) Brookhaven National Laboratory, Upton, H.Y., Jan. 1971.

5. A. Auskern and $w$. Horn in Polymers in Concrete, p. 223, SP-40, American Concrete Instituto, Detroit, 1973.

6. R. W. Davidge and G. Tappin, J. Mat. Sci., 3, 165, 1968.

7. F. Moavenzadeh and R. Kuguel, J. Mat., JyLSA, 4 497, 1969.

8. G. A. Cooper and J. Figg, J. Brit. Ceram. Soc., 71, 1, 1972.

9. J. H. Brown, Mag. Con. Res., 24, 185, 1972.

10. E. Tazawa and $s$. Kobayashi in Polymers in Concrete, p. 57, SP-40, American Concrete Institute, Detroit, 1973.

11. K. Newman in Composite Systems, I. Holliday, ed., p. 401, Elsevier Publishing Co., Iondon, 1966.

12. I. E. Kukacka and G. W. De Puy, ods., Concrete-polymer Materials, Fourth Topical Report, REC-ERC-72-10 and Bar 50328, Brookhaven National Laboratory, Upton, M.Y., Jan. 1972 .

13. A. Auskern, unpublished work. 


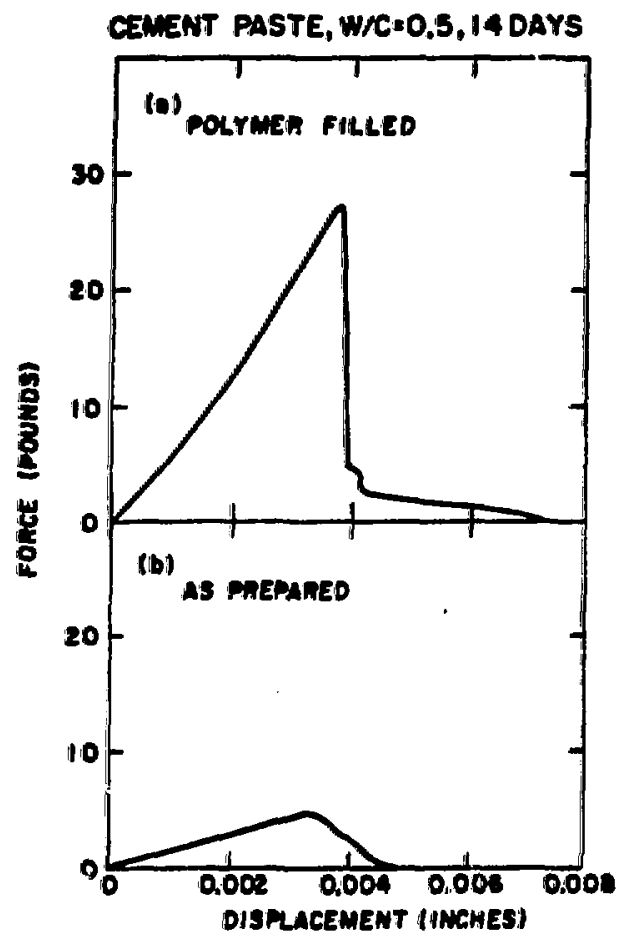

EIG. 1

Typical load-deflection curves for fracture specimens. 


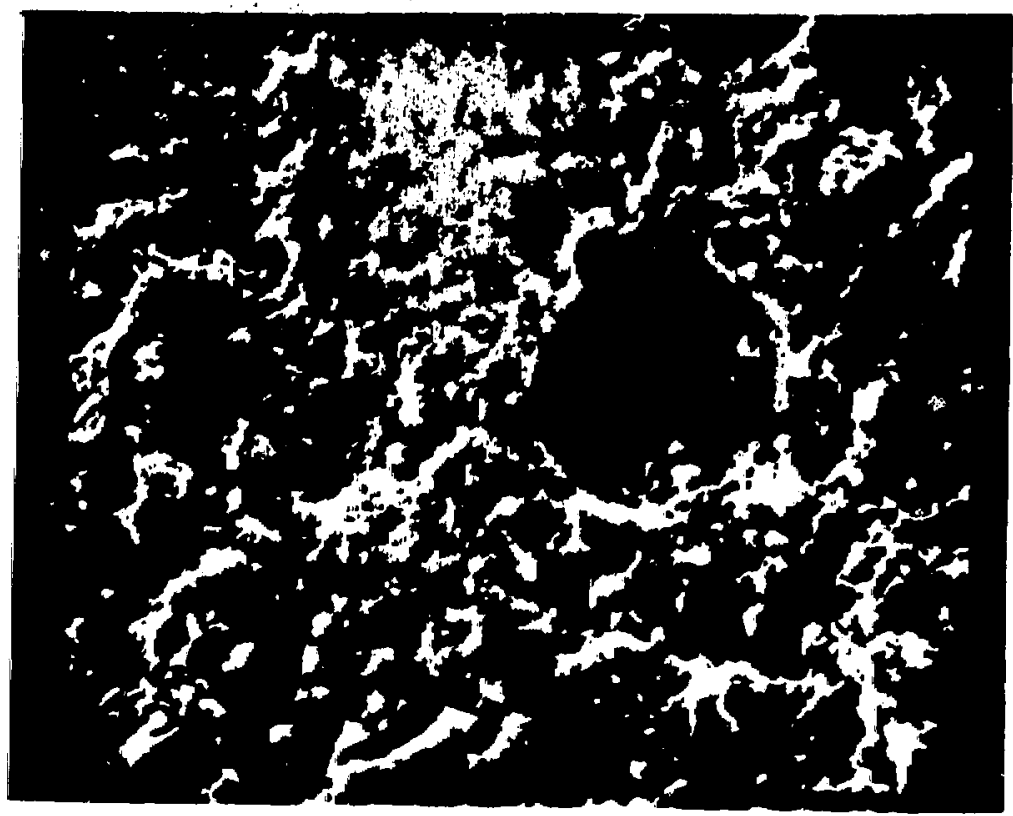

EIG. 2

Fracture surface of unimpregnated sample showing an air void of about 25 microns diameter. Taken at $1000 \mathrm{x}$.

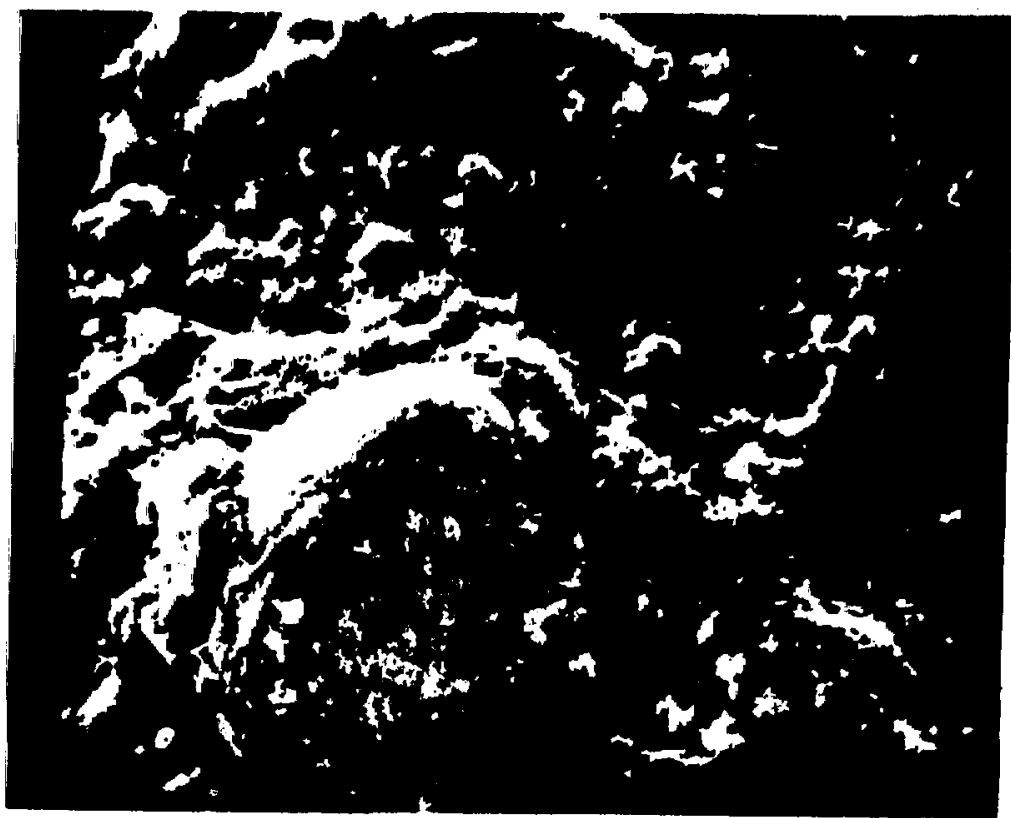

FIG. 3

Practure surface of impregnated sample showing an alr void containing polymer. Taken at $1000 \mathrm{X}$. 